\title{
Attainment of menstrual hygiene by girls in boarding secondary schools in a state in Sub-Saharan Africa
}

\author{
Emmanuel C. Inyang Etoh ${ }^{1 *}$, Uwemedimbuk S. Ekanem², Aniefiok J. Umoiyoho ${ }^{1}$
}

\begin{abstract}
${ }^{1}$ Department of Obstetrics and Gynecology, Obstetrics and Gynaecology, University of Uyo, Uyo, Nigeria
${ }^{2}$ Department of Community Health, University of Uyo, Uyo, Nigeria
\end{abstract}

Received: 09 January 2020

Accepted: 05 February 2020

\section{*Correspondence:}

Dr. Emmanuel C. Inyang-Etoh,

E-mail: emmacol2000@yahoo.com

Copyright: () the author(s), publisher and licensee Medip Academy. This is an open-access article distributed under the terms of the Creative Commons Attribution Non-Commercial License, which permits unrestricted non-commercial use, distribution, and reproduction in any medium, provided the original work is properly cited.

\begin{abstract}
Background: Menarche is the most dramatic manifestation of puberty in girls; unlike the biometric developmental changes that occur at puberty, menarche requires the personal adjustment and response of an affected girl in order to attain good menstrual hygiene. This study was designed to evaluate how boarding secondary school girls manage their menstruation in school, away from the guidance of their parents.

Methods: A cross sectional survey was performed in four public boarding secondary schools in the study area with the aid of structured questionnaires to evaluate how such girls manage their menstruation while in school.

Results: The study population was 975 girls whose survey revealed the mean age at menarche of $12.5 \pm 1.4$ years. Seven hundred and two $(72.0 \%)$ respondents had received sexuality education before onset of menarche. Respondents who attained good menstrual hygiene were 775(79.5\%). Such respondents were those who had received sexuality education $(\mathrm{p}<0.001)$ and those who had access to synthetic sanitary pad $(\mathrm{p}=0.005)$. Duration of the menstrual period and the volume of menstrual blood loss did not affect $(\mathrm{p}=0.219)$ the ability of respondents to attain good menstrual hygiene. Respondents who received sexuality education had about 605 chances of attaining good menstrual hygiene than those who did not receive such education.

Conclusions: A vast majority of the respondents had received sexuality education before onset of menarche and a larger proportion attained good menstrual hygiene. Major factors that positively influenced the girls' capacity to attained good menstrual hygiene were prior sexuality education and access to synthetic sanitary pad.
\end{abstract}

Keywords: Menarche, Menstrual hygiene, Menstruation, Sanitary pad, Sexuality education

\section{INTRODUCTION}

Menarche is the most dramatic manifestation of puberty in girls. While the biometric developmental changes that characterize puberty do not require the active response of the girl, menarche is associated with the need for the girl to make personal adjustments and effort to maintain menstrual hygiene. Puberty brings in its wake, biological, physical, social and psychological changes in the affected girl. ${ }^{1,2}$ Breast development, which often heralds puberty, alerts the girl to the onset of a cascade of biometric changes that will culminate in menstruation in a few years. ${ }^{1,2}$ This natural course of puberty helps the girls to prepare for menarche, when their response and reaction would be needed to ensure menstrual hygiene..$^{2,3}$

Even though there is an age bracket that menarche occurs in girls, the actual age at menarche varies from one girl to the other, depending on her biological, socioeconomic and cultural circumstances., ${ }^{4,5}$ The age bracket that menarche occurs varies from one region to the other, with perhaps the widest recorded range being 10 to 18 years of age. ${ }^{6,7}$ Factors that have been identified to be associated with onset of menarche include the following, parental 
level of education, earlier birth order, smaller family size and higher family income. ${ }^{8,9}$ Additionally, the age at menarche has also been found to exhibit a decline among girls in developing countries, in a trend towards approximately those of their developed country counterparts. ${ }^{5,10}$ While there has been a general decrease in age at menarche in developed countries over the years, decades 1955 to 2009 showed a gradual decline, whereas, the decline during the same period in developing countries was faster. ${ }^{11,12}$

Stake holders in sexual and reproductive health are unanimous on the need and benefit of sexuality education for pre-pubertal girls. Such education makes them aware and expectant, and this helps to prepare the girls psychologically and physically for the personal adjustments and response that is required of them for a successful pubertal period. The benefits of sexuality education for pre-pubertal girls have therefore been well outlined to be of immense benefit to such girls in Europe and America, as well as across the world. ${ }^{13}$ Where sexuality education is lacking among girls who grow into puberty, a number of challenges are imperative with the potential of ruining the sexual and reproductive prospect of affected girls. ${ }^{14}$ In a developing country like Nigeria, efforts at introducing sexuality education to premenarcheal girls seem to be targeted at the prevention of unwanted pregnancies, unsafe abortion and other consequences of unhealthy adolescent sexual behavior. ${ }^{15}$

The need for every girl and woman to attain menstrual hygiene is essential for a normal personal and social health, in the home, in the community, in schools and in emergency situations. ${ }^{16}$ This imperative has been brought to the fore by the World Health Organization, which has designated May 28 of every year as World's Menstrual Hygiene Day. ${ }^{16}$ Few research have been done in developing countries like Nigeria to evaluate how young girls manage and cope with their menarche and subsequent cyclical menstruation. It is particularly of concern to relevant stakeholders on how boarding schoolgirls manage their menstruation while in school, away from the guiding and monitoring roles of their parents and guardians. The few studies conducted in urban areas of Nigeria in a few cities across the country give the impression of a reasonable level of attainment of menstrual hygiene by secondary school girls. ${ }^{17-19}$

No systematic enquiry has been conducted in Uyo, a metropolitan state capital in the south-east health zone of Nigeria. This study was designed therefore to assess the attainment of menstrual hygiene by boarding secondary school girls in Uyo at menarche and during their subsequent cyclical menstruation. It is envisaged that the findings of this study would help parents, guardians, teachers and other stake holders in adolescent health to take steps that will lead to the attainment of menstrual hygiene by menstruating girls. Similarly, policy makers in the education and youth development sectors of the Nigerian economy would see the need to formulate policies to help these girls attain menstrual hygiene in an environment, away from the comfort of their homes. Such attainment would help lay an enduring foundation for a satisfactory and fulfilling sexual and reproductive life through adulthood.

\section{METHODS}

\section{Study design and study area}

This was a cross sectional questionnaire- based descriptive study of girls in four boarding public secondary schools in Uyo metropolis over a four weeks period from $4^{\text {th }}$ to $29^{\text {th }}$ March 2019. Uyo Metropolis is the state capital of Akwa Ibom State, which is one of the 36 states of the federal republic of Nigeria located in the South-east health zone of the country. The state occupies a total land mass of 7,245, 935 square kilometers. ${ }^{20}$

Akwa Ibom state has an estimated population of 5.5 million people. ${ }^{20}$ The state has 252 public secondary schools distributed across the 31 local government areas of the state. There are 64 public secondary schools in Uyo metropolis, with 4 of such schools being girls' only boarding schools.

\section{Subjects and data collection}

Approval to conduct the research was obtained from the Akwa Ibom State Ministry of Education and a copy of the letter of approval was presented to the Principal of each of the secondary schools that was surveyed for their permission. In each of such schools, female students in JS2 to SS1 were assembled in a hall and educated on the nature and purpose of the study. Students who were postmenarcheal for a minimum of 12 months were identified and included in the study, while the other students were asked to leave. The freedom of eligible students to withdraw from the study at any time should they desire to do so was emphasized to them. Students who declined to participate in the study and those who were found to be emotionally unstable were excluded from the study. The questionnaire had been pretested with a cross section of 30 students in a mission boarding girls' secondary school in the metropolis and needed corrections made on the questionnaire to improve the validity and reliability of the questions as a tool for data collection for this survey. Six student- nurses who had been trained on how to administer the questionnaires served as research assistants.

The questionnaire, which was structured and largely precoded were administered by research assistants to all eligible students who consented to participate in the survey. Respondents who needed assistance to ensure adequate completion of the questionnaires were attended to by research assistants and those who needed explanations, the research assistants attended to them. Effort was made to ensure each respondent understood and responded to all the questions before submission. 
Questions were set to obtain background information about the socioeconomic status of respondents' parents. Examples of questions for which a 'Yes' or 'No' response or coded options were provided are: Did you have sexuality education before onset of your first menstruation? When your first menstruation occurred, were you surprised? What did you use as sanitary towel on your first menstruation? What do you use in subsequent menstruations? How much money do you expend on sanitary towel for each monthly menstrual period? etc.

A good menstrual hygiene was said to be attained when the respondent used synthetic sanitary pad at the vulva for absorption of menstrual effluent and changed such pad at least once per day for the duration of the menstrual period. Respondents who changed their sanitary pad twice per day, each time one third or less of the thickness of the pad was soaked were classified as having scanty menstrual flow; respondents who changed their sanitary pad twice per day, each time about two thirds of the thickness of the pad was soaked were classified as having normal menstrual flow; respondents who change their sanitary pad thrice or more times per day, each time completely soaked were classified as having heavy menstrual flow.

\section{Statistical analysis}

Data generated from the study were coded and entered into the software of the Statistical Package for Social Sciences (SPSS), Version 25 Inc. Chicago, Illinois, USA. Thirty-one questionnaires were either incompletely or improperly filled and were excluded from data analysis.
Descriptive statistics were performed for continuous variables and deductions were made using descriptive and inferential statistics. Associations were sought between selected independent variables and access to sexuality education and good menstrual hygiene at menarche and in subsequent menstruations. Multivariate regression of attainment of good menstrual hygiene by respondents were computed for selected independent variables. Association between selected factors and dependent variables like, access to sexuality education and attainment of good menstrual hygiene were computed using the Chi squared test, and differences were considered significant at a $\mathrm{p}$ value of less than 0.05 .

\section{RESULTS}

There were 975 respondents in the study population with the age range of 10-20 years and a mean age of $14.7 \pm 1.40$ years. The age at menarche ranged from 8-20 years of age with a mean age at menarche of $12.5 \pm 1.4$ years. Seven hundred and two $(72.0 \%)$ of the respondents had received sexuality education before onset of menarche; 719 $(73.7 \%)$ of them had their menarche at home and 787 $(80.7 \%)$ had access to sanitary pad. Seven hundred and seventy-five $(79.5 \%)$ respondents attained good menstrual hygiene in the study population.

Table 1 shows that among the $702(72.0 \%)$ respondents who had received sexuality education, the occupations of their fathers were not associated with access to sexuality education, $\mathrm{p}=0.228$. Rather, mothers' education was statistically significantly associated with respondents' access to sexuality education, $\mathrm{p}=0.030$ ).

Table 1: Factors that influenced access to sexuality education and influence of sexuality education on appropriate management of menarche among respondents.

\begin{tabular}{|c|c|c|c|c|}
\hline \multirow{2}{*}{ Variables } & \multicolumn{2}{|c|}{ Sex education } & \multirow{2}{*}{ Total $(\mathrm{n}=975)$} & \multirow{2}{*}{ Statistical indices } \\
\hline & Yes $(n=702)$ & No $(n=273)$ & & \\
\hline \multicolumn{4}{|l|}{ Occupation of father } & \multirow{5}{*}{$\begin{array}{l}\mathrm{df}=3 \\
\square^{2}=4.3677 \\
\mathrm{p} \text { value }=0.228\end{array}$} \\
\hline Unskilled & $107(15.2)$ & $44(16.1)$ & $151(15.5)$ & \\
\hline Semi-skilled & $216(30.8)$ & $101(37.0)$ & $317(32.5)$ & \\
\hline Skilled & $252(35.2)$ & $86(31.5)$ & $338(34.7)$ & \\
\hline Professional & $127(18.1)$ & $42(15.4)$ & $169(17.3)$ & \\
\hline \multicolumn{4}{|l|}{ Education level of mother } & \multirow{5}{*}{$\begin{array}{l}\mathrm{df}=3 \\
\square^{2}=8.9197 \\
\mathrm{p} \text { value }=0.030+\end{array}$} \\
\hline No formal education & $27(3.8)$ & $15(5.5)$ & $42(4.3)$ & \\
\hline Primary & $66(9.4)$ & $34(12.4)$ & $100(10.3)$ & \\
\hline Secondary & $174(24.8)$ & $83(30.4)$ & $257(26.4)$ & \\
\hline Post-Secondary & $435(61.8)$ & $141(51.7)$ & $576(59.1)$ & \\
\hline \multicolumn{4}{|l|}{ Expectation of menarche } & \multirow{3}{*}{$\begin{array}{l}\mathrm{df}=1 \\
\square^{2}=2.6482 \\
\mathrm{p} \text { value }<0.0001+\end{array}$} \\
\hline Yes & 503 (71.6) & $159(58.2)$ & $662(67.9)$ & \\
\hline No & $199(28.4)$ & $114(41.8)$ & $313(32.1)$ & \\
\hline \multicolumn{4}{|l|}{ Type of sanitary towel } & \multirow{5}{*}{$\begin{array}{l}\mathrm{df}=3 \\
\mathrm{p} \text { value }=0.005+^{*}\end{array}$} \\
\hline Tissue paper & $22(3.1)$ & $14(5.1)$ & $36(3.7)$ & \\
\hline Handkerchief & $91(13.0)$ & $56(20.5)$ & $147(15.1)$ & \\
\hline Sanitary pad & $586(83.5)$ & $201(73.6)$ & $787(80.7)$ & \\
\hline Others & $3(0.4)$ & $2(0.7)$ & $5(0.5)$ & \\
\hline
\end{tabular}


Table 2: Factors that influenced ability of respondents to attain good menstrual hygiene at menarche.

\begin{tabular}{|c|c|c|c|c|}
\hline \multirow[b]{2}{*}{ Variables } & \multicolumn{2}{|c|}{ Hygiene at menarche } & \multirow[b]{2}{*}{ Total $(n=975)$} & \multirow[b]{2}{*}{ Statistics } \\
\hline & $\begin{array}{l}\text { Good hygiene } \\
(\mathrm{n}=787)\end{array}$ & $\begin{array}{l}\text { Poor hygiene } \\
(n=188)\end{array}$ & & \\
\hline \multicolumn{4}{|c|}{ Place menarche occurred } & \multirow{7}{*}{$\begin{array}{l}\mathrm{df}=4 \\
\mathrm{p} \text { value } \\
<0.0001+*\end{array}$} \\
\hline Class room & $78(9.9)$ & $30(16.0)$ & $108(11.1)$ & \\
\hline Hostel & $71(9.0)$ & $10(5.3)$ & $81(8.3)$ & \\
\hline Chapel & $15(1.9)$ & $3(1.6)$ & $18(1.8)$ & \\
\hline Playground & $17(2.2)$ & $12(2.2)$ & $29(3.0)$ & \\
\hline Home & $594(75.5)$ & $125(66.5)$ & $719(73.7)$ & \\
\hline Others & $12(1.5)$ & $8(4.3)$ & $20(2.1)$ & \\
\hline \multicolumn{4}{|c|}{ Age at menarche (years) } & \multirow{4}{*}{$\begin{array}{l}\mathrm{df}=2 \\
\square^{2}=3.2667 \\
\mathrm{p} \text { value }=0.195\end{array}$} \\
\hline $8-10$ & $48(6.1)$ & $14(7.4)$ & $62(6.4)$ & \\
\hline $11-14$ & $700(88.9)$ & $159(84.6)$ & $859(88.1)$ & \\
\hline $12-20$ & $39(5.0)$ & $15(8.0)$ & $54(5.5)$ & \\
\hline \multicolumn{4}{|c|}{ Any sexuality education } & \multirow{3}{*}{$\begin{array}{l}\mathrm{df}=1 \\
\square^{2}=12.2516 \\
\mathrm{p} \text { value }<0.001\end{array}$} \\
\hline Yes & $586(74.5)$ & $116(61.7)$ & $702(72.0)$ & \\
\hline No & $201(25.5)$ & $72(38.3)$ & $273(28.0)$ & \\
\hline \multicolumn{4}{|c|}{ Availability of assistance } & \multirow{3}{*}{$\begin{array}{l}\mathrm{df}=1 \\
\square^{2}=10.7695 \\
\mathrm{p} \text { value }=0.001+\end{array}$} \\
\hline Yes & $711(90.3)$ & $154(81.9)$ & $865(88.7)$ & \\
\hline No & $76(9.7)$ & $34(18.1)$ & $110(11.3)$ & \\
\hline \multicolumn{4}{|c|}{ Average cost of sanitary towel (in US\$) } & \multirow{5}{*}{$\begin{array}{l}\mathrm{df}=3 \\
\square^{2}=32.1015 \\
\mathrm{p} \text { value } \\
<0.0001+\end{array}$} \\
\hline$<1$ & $141(17.9)$ & $66(35.1)$ & $207(21.2)$ & \\
\hline 1 & $326(41.4)$ & $76(40.4)$ & $402(41.2)$ & \\
\hline 2 & $235(29.9)$ & $36(19.2)$ & $271(27.8)$ & \\
\hline$>2$ & $85(10.8)$ & $10(5.3)$ & $95(9.7)$ & \\
\hline
\end{tabular}

Table 3: Factors that influenced attainment of good menstrual hygiene in subsequent menstruation among respondents.

\begin{tabular}{|c|c|c|c|c|}
\hline \multirow[b]{2}{*}{ Variables } & \multicolumn{2}{|c|}{ Subsequent monthly hygiene } & \multirow[b]{2}{*}{$\begin{array}{l}\text { Total } \\
(\mathrm{n}=975)\end{array}$} & \multirow[b]{2}{*}{ Statistical indices } \\
\hline & $\begin{array}{l}\text { Good hygiene } \\
(n=775)\end{array}$ & $\begin{array}{l}\text { Poor hygiene } \\
(n=200)\end{array}$ & & \\
\hline \multicolumn{4}{|c|}{ Biological age (in years) } & \multirow{3}{*}{$\begin{array}{l}\mathrm{df}=1 \\
\square^{2}=2.3619 \\
\mathrm{p} \text { value }=0.124\end{array}$} \\
\hline $10-14$ & $310(40.0)$ & $92(46.0)$ & $402(41.2)$ & \\
\hline $15-20$ & $465(60.0)$ & $108(54.0)$ & $573(58.7)$ & \\
\hline \multicolumn{4}{|c|}{ Education level of mother } & \multirow{5}{*}{$\begin{array}{l}\mathrm{df}=3 \\
\square^{2}=15.9866 \\
\mathrm{p} \text { value }=0.001+\end{array}$} \\
\hline No formal education & $25(3.2)$ & $17(8.5)$ & $42(4.3)$ & \\
\hline Primary & $74(9.6)$ & $26(13.0)$ & $100(10.3)$ & \\
\hline Secondary & $217(28.0)$ & $40(20.0)$ & $257(26.4)$ & \\
\hline Post-Secondary & $459(59.2)$ & $117(58.5)$ & $576(59.1)$ & \\
\hline \multicolumn{4}{|c|}{ Access to sexuality education } & \multirow{3}{*}{$\begin{array}{l}\mathrm{df}=1 \\
\square^{2}=11.2639 \\
\mathrm{p} \text { value }=0.001+\end{array}$} \\
\hline Yes & $577(74.5)$ & $125(62.5)$ & $702(72.0)$ & \\
\hline No & $198(25.5)$ & $75(37.5)$ & $273(28.0)$ & \\
\hline \multicolumn{4}{|c|}{ Menstrual period (days) } & \multirow{5}{*}{$\begin{array}{l}\mathrm{df}=2 \\
\square^{2}=11.1885 \\
\mathrm{p} \text { value }=0.011+\end{array}$} \\
\hline $2-3$ & $162(20.9)$ & $63(31.5)$ & $225(23.1)$ & \\
\hline $4-5$ & $487(62.8)$ & $103(51.5)$ & $590(60.5)$ & \\
\hline $6-7$ & $110(14.2)$ & $30(15.0)$ & $140(14.4)$ & \\
\hline$>8$ & $16(2.1)$ & $4(2.0)$ & $20(2.0)$ & \\
\hline \multicolumn{4}{|l|}{ Menstrual blood flow } & \multirow{4}{*}{$\begin{array}{l}\mathrm{df}=2 \\
\square^{2}=3.0412 \\
\mathrm{p} \text { value }=0.219\end{array}$} \\
\hline Scanty & $58(7.5)$ & $16(8.0)$ & $74(7.6)$ & \\
\hline Normal & $600(77.4)$ & $144(72.0)$ & $744(76.3)$ & \\
\hline Heavy & $117(15.1)$ & $40(20.0)$ & $157(16.1)$ & \\
\hline
\end{tabular}


In Table 2, $586(83.5 \%)$ respondents who had received sexuality education significantly had access to sanitary pad to maintain menstrual hygiene at menarche, $\mathrm{p}=0.005$ and respondents who had received sexuality education also significantly attained good menstrual hygiene, $\mathrm{p}<0.001$. Respondents who had availability of an older-female assistance during menarche also significantly attained good menstrual hygiene than others, $\mathrm{p}=0.001$. Respondents who expended a minimum of US\$1 on sanitary towel per period highly significantly attained menstrual hygiene than those who expended less, $\mathrm{p}<0.0001$.

Table 3 shows that respondents whose mothers had attained secondary level of education or higher significantly attained good menstrual hygiene, $\mathrm{p}=0.001$. Respondents with duration of menstrual period of 4 days or more significantly attained good menstrual hygiene than those with fewer days of menstruation, $p=0.011$. The volume of menstrual blood loss had no association with the attainment of menstrual hygiene among respondents, $\mathrm{p}=0.219$.

In Table 4, respondents who expended over a US\$1 on sanitary towel per period were 3 times more likely to attain good menstrual hygiene than those who expended less. Respondents whose menstrual period lasted for 4 or more days were $65 \%$ more likely to attain good menstrual hygiene than those who menstruated for fewer days. Respondents who received sexuality education had about $60 \%$ chances of attaining good menstrual hygiene than those who attained menarche without sexuality education.

Table 4: Multivariate regression of good menstrual hygiene for regular menstruation of respondents.

\begin{tabular}{|c|c|c|c|c|}
\hline Variable & & Odds ratio & 95\% CI & $\mathrm{p}$ value \\
\hline \multirow{4}{*}{ Cost of sanitary towel (in US\$) } & $<1$ & Ref & & \multirow{4}{*}{$\begin{array}{l}<0.0001+ \\
<0.0001+ \\
0.005+\end{array}$} \\
\hline & 1 & 3.02 & $2.04-4.45$ & \\
\hline & 2 & 3.68 & $2.33-5.82$ & \\
\hline & $>2$ & 17.52 & $2.33-131.58$ & \\
\hline \multirow{4}{*}{ Menstrual period (days) } & $2-3$ & Ref & & \multirow{4}{*}{$\begin{array}{l}0.010+ \\
0.742 \\
0.627\end{array}$} \\
\hline & $4-5$ & 1.65 & $1.13-2.42$ & \\
\hline & 6-7 & 1.09 & $0.64-1.86$ & \\
\hline & $>8$ & 1.34 & $0.41-4.40$ & \\
\hline \multirow{4}{*}{ Education level of mothers } & No formal education & Ref & & \multirow{4}{*}{$\begin{array}{l}0.086 \\
0.001+ \\
0.013+\end{array}$} \\
\hline & Primary & 2.01 & $0.91-4.47$ & \\
\hline & Secondary & 3.43 & $1.65-7.16$ & \\
\hline & Post-Secondary & 2.38 & $1.20-4.71$ & \\
\hline \multirow{2}{*}{ Access to sexuality education } & No & Ref & & \multirow{2}{*}{$0.009+$} \\
\hline & Yes & 1.59 & $1.12-2.26$ & \\
\hline
\end{tabular}

\section{DISCUSSION}

Menarche is the most dramatic event that characterizes puberty; and it is incumbent on the menstruating girl to take steps to attain a good menstrual hygiene when the occasion arises. For girls in boarding secondary schools, the attainment of a good menstrual hygiene could be a challenge, especially, when sexuality education is lacking, and the resources needed are not readily accessible. The reported age range at menarche of 8 to 20 years and a mean age at menarche of $12.5 \pm 1.4$ years obtained in this study are reflective of the menarcheal profile of girls in the study area, as well as the subregion, because the secondary schools surveyed are clusters of girls from both urban and rural areas of the state and the neighboring states that constitute the southeast health zone of Nigeria. ${ }^{21}$ These findings are comparable to results obtained from studies in other health zones of Nigeria, where menarcheal age was found to range from 10 to 18 years, with an average age at menarche of 13.1 years of age. ${ }^{5-7}$ Respondents that received sexuality education before onset of menarche were $702(72 \%)$, and this rather high level of expression of sexuality knowledge is in agreement with findings from other studies in Nigeria. ${ }^{22,23}$ Notwithstanding this seemingly high level of sexuality knowledge among girls, none of the studies interrogated respondents on their comprehensive knowledge of the contents of sexuality education. Curiously, such studies have used the terms, sexuality education, sex education and puberty education synonymously or interchangeably, which raises concern about the uniformity of this concept even among researchers. A country like Nigeria focuses on a limited aspect of sexuality education among pubertal girls; this often centers on issues of unhealthy sexual behavior and the consequences of such misconduct among girls. ${ }^{15}$ It does not seem that sexuality education is commenced at home by the parents as expected, as a survey of factors that influenced access to sexuality education among school girls in Hawaii revealed that, first hand, $80 \%$ of teachers taught some form of sexuality education to their students, whereas only $54.4 \%$ taught comprehensively on sexuality education. ${ }^{24}$ Among the respondents who had received sexuality education, the level of education of their mothers positively influenced $(\mathrm{p}=0.03)$ their access to sexuality education, unlike their fathers' occupation. 
Conversely, respondents whose fathers belonged to skilled and professional occupations were significantly associated with earlier age at menarche, as against their mothers' level of education. These findings have confirmed the fact that a higher socioeconomic status of the family is associated with younger age at menarche. ${ }^{8,9}$ Seven hundred and seventy five $(79.5 \%)$ respondents attained good menstrual hygiene in the study population, similar to results from other studies. ${ }^{25-27}$ Factors that positively impacted on the girls' capacity to attain good menstrual hygiene at menarche were prior access to sexuality education, availability of assistance during menarche and access to synthetic sanitary pad. These findings agreed with results from similar studies in other health zones of Nigeria and in the West African Subregion. ${ }^{25-27}$ It was however instructive to note that the duration of the menstrual period and the volume of menstrual blood loss did not influence the attainment of good menstrual hygiene by respondents; rather, respondents who expended spent over US\$1 on their sanitary towel were more likely, ( $p$ value $=0.0001)$ to attain good menstrual hygiene than those who expended less. Factors that were found to undermine the attainment of good menstrual hygiene by respondents in studies conducted outside the West African sub-region were, younger age of the respondents, low socio-economic status of the parents, stress and bullying from their male counterparts. ${ }^{28,29}$ Multivariate regression of factors that influenced attainment of good menstrual hygiene among respondents identified, prior access to sexuality education as the strongest factor that influenced school girls' capacity to attain good menstrual hygiene, justifiably so because such respondents had been psychologically and materially prepared for the occurrence. This revelation underscores the importance of sexuality education for pre-pubertal girls, which helps them to have a satisfactory experience of their passage through puberty into womanhood. Sexuality education should however be comprehensive, covering the biometric developmental changes expected at puberty, menarche and menstrual hygiene, as well as the subsequent cyclical menstruation that follow. ${ }^{13,14}$ Sexuality education of course includes, the sexuality of girls and boys and the temptation of sexual experimentation, with its attendant consequences of unhealthy sexual behavior, unplanned pregnancy, sexually transmitted infections and unsafe abortion. ${ }^{15,30}$

\section{CONCLUSION}

The conclusion from this study is that the age at menarche of girls in the study population is similar to other health zones of Nigeria, as well as other regions of the world. A large proportion of the respondents had received sexuality education, even though the content of such education was not evaluated in the study. Menstrual hygiene was attained by most respondents who had received sexuality education, as well as those who had access to synthetic sanitary pad. The strongest factor that influenced attainment of menstrual hygiene among the respondents was prior access to sexuality education.

\section{Recommendations}

Sexuality education should be initiated at home by the parents of pre-pubertal girls before they attend secondary school; the school should merely provide another opportunity for formal and comprehensive sexuality education by the teachers. Personnel in charge of the wellbeing of girls in boarding secondary schools should pay attention to menarcheal and menstruating girls for the purposes of assistance and support to help them attain good menstrual hygiene.

\section{ACKNOWLEDGMENTS}

The researchers are deeply grateful to the principals and teachers of the schools where students were surveyed, for their support and assistance during the data collection, when the questionnaires were administered to their students.

Funding: No funding sources

Conflict of interest: None declared

Ethical approval: The study was approved by the Institutional Ethics Committee

\section{REFERENCES}

1. Nzeako HC, Ezejindu DN, Iwunze AB and Obinwa BN. Pubertal development in Nigerian Igbo girls. J Pharmaceut Sci. 2015;2(4):45-51.

2. Eyong ME, Ntia HU, Ikobah JM, Eyong EM, Uket $\mathrm{H}$, Enyiuma C, et al. Pattern of pubertal changes in Calabar, South-south Nigeria. PAMJ. 2018;31:20-31.

3. Fakeye O, Fagbule D. Age and anthropometric status of Nigerian girls at puberty: implication for the introduction of sex education into secondary schools. West Afr J Med. 1990;9(3):226-31.

4. Tunua KA, Adamu AN, Hassan MA, Ahmed Y, Ekele BA. Age at menarche among schools girls in Sokoto, Nothern Nigeria. Ann Afr Med. 2012;2(11):103-7.

5. Otobo TM, Onyemauche Osah, Paul NJ. Age at menarche in Nigerian adolescent girls case study: (Igbo, Yoruba, Hausa and Engenni tribes of Nigeria). Eur J Pharm Med Res. 2019;5(1):364-8.

6. Tijani AM, Awowole IO, Badejoko OO, Badejoko $\mathrm{BO}$, Ijarotini AO, Loto OM. Is menarche really occurring earlier? A study of secondary school girls in Ile Ife, Nigeria. TJOG. 2019;1(36):112-6.

7. Adefuye PO, Odusoga OL, Adefuye BO, Akindele RA. Age at menarche and menstrual pattern in secondary school girls in Sapamu. NJCP. 2010;1(13):109-13.

8. Nwankwo M, Damborno B, Oliver HW. Family background and age at menarche among secondary school girls in Nigeria. JECA. 2017;2(16):77-82.

9. Ofuya ZM. The age at menarche in Nigerian Adolescents from two different socioeconomic classes. Online J Health Allied Scs. 2007;4(6):1-5. 
10. Oduntan SO, Ayeni O, Kale OO. The age of menarche in Nigerian girls. Ann Hum Biol. 2009;3(3):267-74.

11. Talma H, Schonbeck Y, Dommelen PV. Bakker B, Buuren SV, Hirasing RA. Trends in menarcheal Age between 1955 and 2009 in the Netherlands. PLoS One. 2013;8(4):e60056.

12. Wyshak G, Frisch RE. Evidence for a secular trend in Age of menarche. N Engl J Med. 1982;306:1033-5.

13. Weaver H, Smith G, Kippax S. School-based sex education policies and indicators of sexual health among young people: a comparison of the Netherlands, France, Australia and the United States of America. J Sex Educat Sexual Soci Learning. 2007;2(5):171-88.

14. Crockett LJ, Deardorff J, Johnson M, Irwin C, Petersen AC. Puberty education in a global context: knowledge gaps, opportunities, and implications for policy. J Res Adolesi. 2019;1(29):177-95.

15. Shortridge JL. Nigeria guidelines for sexuality education introduced at ceremony in Lagos. Siecus Rep. 1997;25(2):4-7.

16. World Health Organization (WHO). World Health Days: Menstrual Hygiene Day - May 28. Executive Board 144th session provisional agenda item 7.6 of WHO 2019;1-7. A70/12:1-7.

17. Adika VO, Ayinde MO, Jack-Ide IO. Selfcare practices of menstrual hygiene among adolescent schoolgirls of Amassoma community, Bayelsa State. Int J Nurs Midwifery. 2013;5(5):99-105.

18. Akinwaare MO, Akindele OM, Oluratosin OA. Menstrual hygiene practices among adolescents in selected secondary schools around the University of Ibadan, Nigeria. JMBR. 2016;1(15):92-101.

19. Garba I, Rabiu A, Abubakar IS. Menstrual hygiene among adolescent schoolgirls in Kano. TJOG. 2018;2(35):153-7.

20. Akwa Ibom State Ministry of Education (AKSMOE). Number of Schools and Educational facilities in the state. Updated statistics of the Akwa Ibom State Ministry of Education for the year 2018. Available

at: https://mhrd.gov.in/sites/upload_files/mhrd/files/stati stics-new/ESAG-2018.pdf. Accessed 5 March 2018.

21. National Population Commission (NPC) Nigeria. Health Zones in Nigeria. Nigeria National
Demographic and Health Survey (NDHS). 2017; 10:4-5.

22. Akanda TM, Akanda AA. Knowledge and perception of sexuality education among students of rural secondary school in kwara state, Nigeria. Niger Med Practr 2007;52(3):55-9.

23. Orji E, Esimai O. Introduction of sex education into the Nigerian schools: The parents' teachers' and students' perspectives. J Obstet Gynecol. 2003;23(2):185-8

24. Woo G, Soon R, Thomas JM, Kaneshiro B. Factors affecting sex education in the school system. J Pediatr Adolesi Gynecol. 2011;24(3):142-6.

25. Aniebu UU, Aniebu PN, Nwankwo TO. The impact of pre-menarcheal training on menstrual practices and hygiene of Nigerian schoolgirls. The PAMJ. 2009;2:9-19.

26. Ameade EPK, Majeed SF. Improving girl child education and menstrual hygiene through free sanitary pad provision to secondary school girlsopinion of female University students in Ghana. J Health Edu Res Dev. 2015;3:143-51.

27. Kovir E, Okwara FN, Okumbe G. Menstrual hygiene management practices among primary school girls from a pastoralist community in Kenya: a cross sectional survey. PAMJ. 2018;31:222-32.

28. Omidvar S, Begum K. Factors influencing hygiene practices during menses among girls from south India: a cross sectional study. Int J Collabor Res Intl Med Pub Health. 2011;2(2):411-23.

29. Lahme AM, Stern R. Factors that affect menstrual hygiene among adolescents schoolgirls: A case study from Mongu District, Zambia. Women's Reprod Health. 2017;3(4):198-211.

30. Adinma JI, Adinma ED. Ethical considerations in women's sexual and reproductive health care. Nigerian J Clin Pract. 2009;12(1):11-6.

Cite this article as: Inyang Etoh EC, Ekanem US, Umoiyoho AJ. Attainment of menstrual hygiene by girls in boarding secondary schools in a state in SubSaharan Africa. Int J Reprod Contracept Obstet Gynecol 2020;9:984-90. 